\title{
SEX OF PLACE: MEDIATED INTIMACY AND TOURISM IMAGINARIES
}

\author{
Elsa Soro ${ }^{1}$ \\ Ostelea School of Tourism and Hospitality, \\ Lleida University, Spain \\ esoro@ostelea.com
}

\begin{abstract}
The capillary diffusion of digital and mobile technologies has deeply changed both the way of travelling and loving. Against this changing context, the aim of this paper is to examine the relationship between tourism discourse and online-dating discourse. Through analysis of a sample of Tinder profiles, the relationship between the self-presentation and the touristic space experience will be scrutinized. The main hypothesis that drives this work is that different ways of being attractive and seductive on dating apps correspond to specific, current narratives and typologies of tourism.

The article maintains that discourse of mediated intimacy platforms borrow its themes from tourism imaginaries. Consequently, tourism discourse shapes the different modes of self-presentation in online intimacy.

\footnotetext{
${ }^{1}$ The research for this paper is funded by the Spanish Ministry of Economy, Industry and Competitiveness (POLITUR project. CSO2017-82156-R) and AEI/FEDER, EU and by the Department of Research and Universities of the Catalan Government (2017SGR22).
}

Digital Age in Semiotics \& Communication, Vol. II, 2019, Pp. 93-102 https://doi.org/10.33919/dasc.19.2.6 
Keywords: online dating, intimacy, tourism, tinder, spatial self

\section{Sex and love on the move}

The capillary diffusion of digital and mobile technologies has deeply changed both the way of travelling and loving.

On one hand, in the domain of online courtship, geo-localization allows the location of potential partners to be visualised. As such, physical distance happens to be a crucial criterion in the potential partners' ecology of choice. On the other hand, the travel industry relies more and more on new technologies in order to guarantee a more customized place experience: new technologies are therefore meant to enhance more authentic tourism experiences.

By analyzing such trends, literature has focused on the commodification processes of either sex and intimacy or tourism. On one side, sociologists and psychologists have stressed how the penetration of "marketing language and techniques into the role of interpersonal relationships" (Illouz 2013) has driven to an interchangeability and to a disembodying of erotic bonds. On the other side, critical studies in tourism (Arias Sanz \& Qualieri Domínguez 2016; O' Regan \& Chloe 2016) have pointed out how the raising of new technology-driven products and services in tourism have contributed to the commodification of traditional values such as reciprocity and authenticity. The way in which the so-called "collaborative" platforms have contributed to nurture speculation and gentrification processes has been extensively analysed.

Consequently, in the so-called digital age, the two domains, love and tourism, seemto be closely connected also at a representational and discursive level. Building on this hypothesis, the aim of this paper is to examine the different classifications of tourism practices within online dating discourse. Through an analysis of a sample of Tinder profiles, the relationship between self-presentation and space experience will be scrutinized. The hypothesis that drives this work is that the different ways of being attractive and seductive in dating apps are correspondent to specific, current tourism narratives.

If it is generally agreed that being portrayed in a nice setting aims at catching "likes" in overall social network-scapes, the way in which various poses and compositions, as borrowed from the tourism discourse and as used by the seduction discourse, has not been extensively studied. After a short contextualization of place in the globalization age, this paper will focus on an analysis of the Tinder profile set-up. In the discussion, typologies of different ways of being a tourist will be broken down and a basic semantic opposition from which all the other categories have stemmed will be identified. The conclusion will point out future lines of the research within the semiotics of culture, in order to explore the liminal space between the semiosphere of tourism and mediated intimacy. 


\section{2. (No) sense of place}

Much has been said about the disappearance or the irrelevance of place in concomitance with the digital revolution. Multidisciplinary literature has stressed how the ubiquity of mobile technologies tends to emancipate people from place, whereas the physical location seems to not matter anymore.

In No Sense of Place, Joshoua Meyerowitz (1985) focuses on how new media have changed the frame of public and private spheres, and in doing so, they have contributed to weakening the significance of physical place as a determinant of social situations. Manuel Castells (2002: 500) stresses how space becomes blurred in what he calls the connectionist world, a world in which networks "constitute the new social morphology of our societies, and the diffusion of networking logic substantially modifies the operation and outcomes in processes of production, experience, power, and culture." After the postmodernist claim for increasing "time-space distancing" (Giddens 1990) and compressing time (Harvey 1990), due to the invention of mobile communication, belonging to a place has been replaced by belonging to a specific communication network. When taking a step further in virtual reality environments, physical presence is even more questioned.

It goes without saying that the capillary diffusion of new mobile and digital technologies has strongly reshaped the intimacy and courtship domain as well. The concept of liquid love (Bauman 2003) suggests that technological change has eroded lifelong monogamous partnerships and has transformed dating into an ultimate type of gamification tool. Technologies have been argued to cause a strong influence in sexual and intimate practices, moving towards a progressive loss of the importance of face to face encounters. Hence, the role of physical location as the setting for romantic/sexual encounters is also said to be affected and replaced by the online environment.

Nevertheless, this work concedes that performance and consumption of place still exercise a strong influence over the courtship domain. The representation of place in new and digital media visual rhetoric is far from disappearing: this is clearly reflected in the massive presence of place-related posts in social networks, as will be discussed in the following section.

\section{Place (in motion) is still there}

Within the new mobilities paradigm, the British sociologist John Urry noticed that in the current age, frequent movement in time and space is nonetheless the "meetingness" that network capital entails. According to Urry, the possibility of being together in a place and having a face-to-face conversation are the basis of social life that "occurs at a distance" (2003: 155).

Just when a terrific increase in travelling has been registered, location is meant to serve a crucial role in social media visual discourse. In other words, 
while allowing people to be connected at a distance, the new technologies of mobility entail anchors and mooring to place. Ever since geo-localized devices allow users to share their on-time location, social networks share plenty of location-related posts. Through photographs, status updates, 'likes', checkins, and tags, social networks grant "glamour" to place. This is the hypothesis with which Gössling and Stavrinidi (2016) analyzed how in social networks, complex patterns of competition for network capital are based on mobilities and on tourist consumption/performance of the place.

In line with the fact that international tourist arrivals have grown year by year ${ }^{2}$, sociologist Marco D'Eramo (2017) has defined our age as the age of tourism and therefore, it may be argued that undoubtedly tourism can be considered as the "industry of place".

Following the reasoning so far, how does the domain of mediated love and intimacy interact with place and, more precisely, with the touristic consumption and experience of place? The next section will analyse how place representation, embedded in online dating discourse, plays a crucial role in enhancing intimate discourse.

\section{Mediated intimacy of space}

With the recent proliferation of dating apps, at least two new elements have been changing the relationship between space, mobility and intimacy.

First, unlike dating websites, the portability of dating apps potentially allows dating app-users to arrange real-time encounters and, by so doing, this immediacy causes a strong impact on the temporality of dating.

Secondly, thanks to geo-localization, the distance between potential matches can be visualized. The fact that on Tinder the greatest distance for choosing potential mates is only 100 miles ultimately makes physical distance a crucial factor in the ecology of choice.

Despite the differences in their mission, scope, services and affordances, all of the most popular dating apps emphasise the importance of their location-based features and, by so doing, accentuate the association between self and location.

Grindr, the popular hook-up app for gay people, makes the distance between potential partners visible; the principle behind Happn is "find the people you've crossed paths with". OKCupid lets users know when a potential good match is nearby. Tinder's motto is "interesting people nearby." Furthermore, this platform has already launched the new feature Places, designed to discover the people "who hang out where you hang out." Such

\footnotetext{
${ }^{2}$ According to UNWTO 2017 website (http://www2.unwto.org/ last access on 07/04/2019).
} 
new implementations reinforce the hypothesis that identity is strictly plotted in relation to the places people frequent in their leisure time.

With this assumption in mind, this analysis will scrutinize the self presentation images in Tinder profiles with the aim of unlocking the extent to which the elements that inhabit Tinder's visual discourse refer to place, and, by doing this, engage the tourism domain.

Tinder has been selected for this purpose, based on its popularity in the age range considered by the research (25-45-years olds), and due to its high number of users worldwide. Such popularity turns Tinder into an important observatory for the monitoring of lifestyle transformation, and co-extensively the whole domain of leisure.

\section{Self-presentation scenography in Tinder profiles}

This analysis considers over 100 Tinder profiles (aged 30-45; male 70\%, female $30 \%$ ) and focuses on profile composition. It should be taken into account that someone's picture is the first thing other users see. In order to maximize the chance that someone "swipes right", users are thus forced to present themselves in the most flattering way possible.

Accordingly, users choose a specific scenography for staging an alleged desirable self, by choosing those elements which are assumed to be particularly representative of an appealing lifestyle. In so doing, profiles disclose a selection of identity elements while hiding others, in Eco's terms (1979).

By examining the context of locative mobile social networking, Sutko and de Souza e Silva (2011) use the concept of the presentation of place as an expansion of Goffman's (1959) presentation of self in everyday life. We are building on this idea to consider location (and the performance of location) as the driver of a specific lifestyle which, in turn, foreshadows different typologies of viewers and, by extension, foresees different typologies of relationships. Relying on this, one might argue that Tinder users stage a specific tourist's postcard through which the exposition of attractiveness is deployed.

In order to clarify this idea, the coding scheme for the analysis of profile images has included either place features or activities carried out in place, since places have been continuously given new meanings according to the actions that users perform there.

Categories have been chosen on the basis of the more general attributes of space and of leisure/tourism activities. 


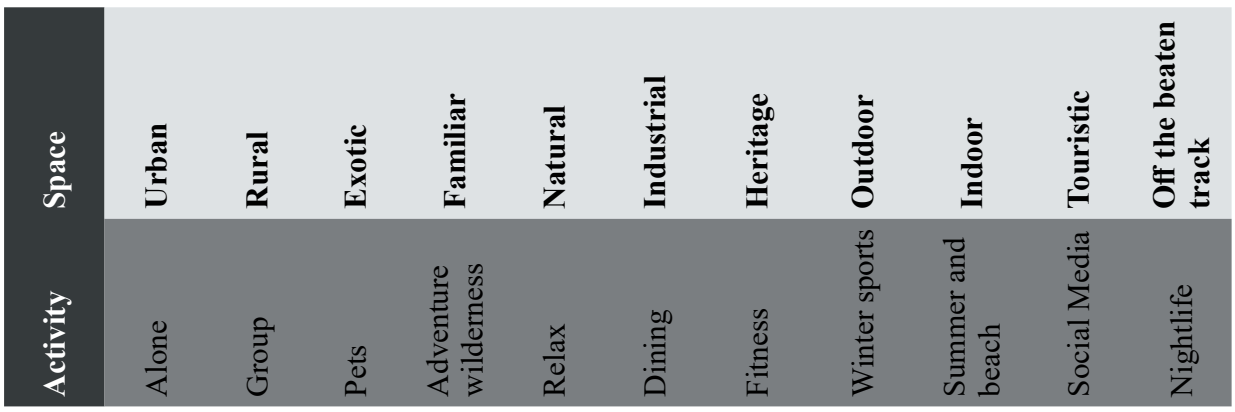

\section{Ordinary/extraordinary tourism}

According to Greimas (1970), the condition for grasping any meaning lies in an elementary system of relations, articulated in the semiotic square. The findings from this visual content analysis show how two opposing attitudes towards place experience emerged.

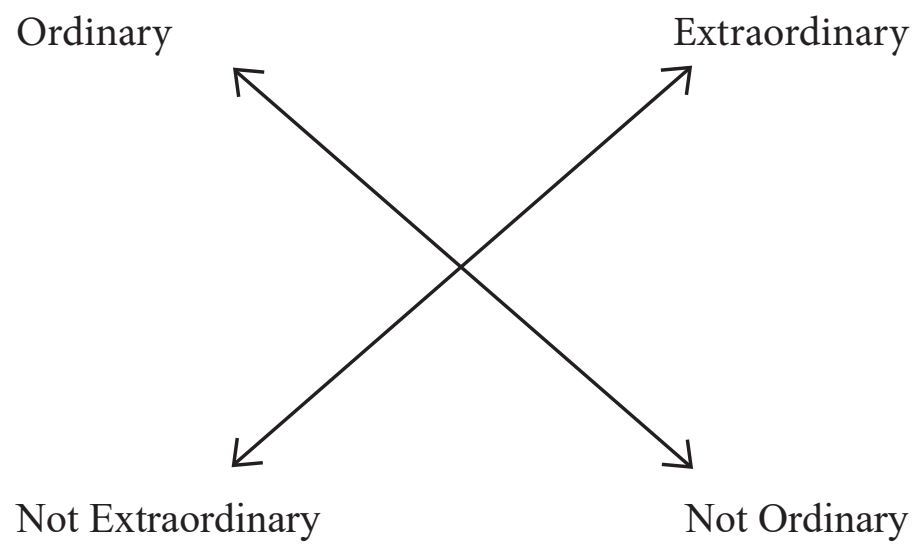

Fig. 1: Semiotic square

We have defined such positions as Ordinary vs Extraordinary. From this basic opposition, two terms arise, called contradictory seme: Not Ordinary and Not Extraordinary. In the following analysis the four terms, each corresponding to a position on the square, will be broken down, and we will identify different typologies of being a tourist and performing tourism.

\section{Ordinary}

This term includes and grasps all the images that portray users in very famous and well-known tourism sites, such as Tour Eiffel, Machu Pichu, Pisa Tower, Brooklyn Bridge. It also comprehends the "standard" but anonymous 
tourism locations i.e. tropical beaches where the actors perform "typical tourist ways of life", such as drinking a cocktail at sunset, or lying on a beach. We can define this kind of performing tourism as massive tourism.

\section{Extraordinary}

This position refers to all the images that depict alternative and/or neglected, remote settings and locations where actors experience any kind of activities that connect with nature, wilderness, local community, exotic fauna etc. Some of the more frequent self-presentations within this position are: hiking, diving, surfing, backpacking, etc. The typology of tourism niche (or attitude) that best defines this series of images is "alternative tourism".

\section{Not Ordinary}

This category refers to users portrayed in a not well identified environment (mostly urban settings) where they seem to be perfectly integrated, by performing daily actions such as taking the bus or the metro, walking in the street. Even if biographical data indicates that this place is not their hometown, they look like as if it might be. Such tourism typology has been defined as "cosmopolitan".

\section{Not Extraordinary}

This category gathers images and profiles that establish an intentionally polemic relation with any tourist or adventurous attitude toward the place. Users within this position describe themselves as a NO-surfer or a NO-climber by ironically distinguishing themselves from the high number of self presentations tied to these kinds of high-adrenaline activities (most frequently staged by male users).

Another occurrence in this position is when the "naked" place appears without any person in it. This may suggest an iconoclastic idea of no-relation with the place, no-performance of the place. This tourism attitude is defined as anti-tourist.

\section{As a conclusion: for a "touristification" of love}

Without claiming to be exhaustive, this study has raised questions about the connections (both on practice and representation levels) between the love/courtship domain and the travelling/tourism one.

Bearing in mind the concept of "spatial self" performed throughout digital application, as introduced by Sutko and De Souza e Silva (2011) and further developed by Schwartz and Halegoua (2014), this research is an attempt to rethink these geographic traces as tourist consumption/experiences of 
the place. Whereas scholars have scrutinized the use of location-based social media and the consequent documentation of physical mobility and how photos are plotted in relation to geographic locations showing, we have tried to touch upon the role of tourism in spatial representation of the self.

In line with the theory of tourism as analytics "with which to interrogate dynamic social processes" (Minca \& Oakes 2014), we have proposed tourist poses and gesture as a lens through which to read seduction strategies. In other words, mediated intimacy vision arguably borrows from tourism imaginaries and consequently tourism discourse shapes the different modes of self-presentation in online intimacy. While we argue that the capillary diffusion of digital and mobile technologies has deeply changed both the way of travelling and loving, we also suggest that the two domains mutually influence each other.

In some ways, the opposition between ordinary vs. extraordinary is either a performance of place or a performance of intimacy (a way to be a tourist, a way to be a lover). Such opposition (and the other positions generated by it) is just an ultimate update of the traditional distinction between tourist vs. traveller. The alternative tourist is the contemporary modern adventurer, Simmel (1997) depicted as someone seeking new experiences in new environments.

To be more provocatitve, could this intermingling lead to a "touristification of love" and/or "lovification of tourism"? In this regard, further research should approach this question using the tools of cultural semiotics in order to grasp that space in between, a space that is contagious and porous in relation to different meaning processes. 


\section{References}

Arias Sanz, Albert \& Quaglieri Domínguez, Alan. 2016. Unravelling airbnb: Urban perspectives from Barcelona. Built Environments and "Glocalized" Spaces. p. 209-228.

Bauman, Zygmunt. 2003. Liquid Love. On the Frailty of Human Bonds. Cambridge: Polity.

Castell, Manuel. 2002. Local and Global: Cities in the Network Society. Tijdschrift voor Economische en Sociale Geografie. Vol. 93, No. 5, p. 548-558.

David, Gaby \& Cambre, Caroline. 2016. Screened Intimacies: Tinder and the Swipe Logic. Social Media + Society.

D'Eramo, Marco. 2017. Il selfie del mondo. Indagine sull'età del turismo. Milano: Feltrinelli.

Harvey, David. 1990. The Condition of Postmodernity. Oxford: Blackwell.

Eco, Umberto. 1979. Lector in Fabula. Milano: Bompiani .

Giddens, Anthony. 1990. The Consequences of Modernity. Stanford, Calif.: Stanford University Press.

Goffman, Ervin. 1959. The presentation of self in everyday life. Garden City, N.Y. : Doubleday.

Gössling, Stefan \& Stavrinidi, Iliada. 2016. Social Networking, Mobilities, and the Rise of Liquid Identities. Mobilities, Vol. 11, No 5, p.723-743.

Greimas Algirdas Julien. 1970. Du sens 1. Paris: Seuil.

Hobbs, Mitchell, Owen, Stephen, \& Gerber, Livia. 2017. Liquid love? Dating apps, sex, relationships and the digital transformation of intimacy. Journal of Sociology, Vol.53, No.2, p.271-284.

Illouz, Eva. 2012. Why Love Hurts: A Sociological Explanation. Cambridge: Polity.

Meyerowitz, Joshoua. 1985. No Sens of Place. The Impact of the Electronic Media on Social Behavior. Oxford: Oxford University Press. 
Minca, Claudio \& Oakes, Tim. Tourism After the Postmodern Turn. In Lew, Alan, Hall, Micheal \& Allan, Williams (eds.), 2014. The Wiley Blackwell companion to tourism. Hoboken, NJ: Wiley-Blackwell, Wiley, pp. 294-303.

Leone, Massimo. (Forthcoming). The Semiotics of the Face in the Digital Era, forthcoming. In Leone, Massimo, ed. Forthcoming. Il volto / The Face Monographic issue of Lexia, 31-32, Rome: Aracne.

O’ Regan, Michael \& Choe, Jaeyeon. 2017. Airbnb and Cultural Capitalism: Enclosure and Control within the Sharing Economy. Anatolia, Vol. 28, No. 2, p.163-172

Ranzini, Giulia., \& Lutz, Christoph. 2017. Love at first swipe? Explaining Tinder self-presentation and motives. Mobile Media \& Communication, Vol. 5, No.1, p.80-101

Sheller, Mary \& Urry, John. 2003. Mobile Transformations of 'Public' and 'Private' Life. Theory, Culture and Society. Vol. 20, No. 3, p. 107-125.

Simmel, Georg. 1997 [1910]. The Adventure. In Frisby, David \& Featherstone, Mike. (eds.), 1997. Simmel on Culture, London: Sage, p.221-232.

Schwartz, Raz \& Halegoua, Germaine. 2014. The spatial self: Location-based identity performance on social media. New Media \& Society. Vol. 17, No. 10, p 1643-1660.

Sutko, Daniel \& de Souza e Silva Adriana. 2011. Location-aware Mobile Media and Urban Sociability. New Media and Society. Vol.13, No 5, p. $807-823$. 